\title{
2020 Vision: Envisioning a new generation of STEM learning research
}

\author{
Lynn D. Dierking ${ }^{1} \cdot$ John H. Falk ${ }^{2}$
}

Received: 9 October 2015/Accepted: 9 October 2015/Published online: 1 February 2016

(C) Springer Science+Business Media Dordrecht 2016

\begin{abstract}
In this issue, we have compiled six original papers, outcomes from the U.S. National Science Foundation (US-NSF)-funded REESE (Research and Evaluation on Education in Science and Engineering) 2020 Vision: The Next Generation of STEM Learning Research project. The purpose of 2020 Vision was to re-envision the questions and frameworks guiding STEM research in the twenty-first century, given that notions of learning have changed significantly in the last decade. The papers present diverse research principles that emerged from an initial 2020 Vision conference at Oregon State University (OSU), were then vetted more broadly with the science education community nationally and internationally, and presented in a public 2020 Vision symposium series also at OSU. Individually and as a group, these papers argue that if STEM learning is lifelong, life-wide and life-deep, research designs need to cut across the diverse settings and investigate the multiple contexts and media in which learners live and interact. Authors call for research paradigms that holistically reflect questions of the "what, when, where, why, how and with whom" of STEM learning. Associated Forum papers respond and expand the conversation by critically examining the recommended research principles and in some cases, challenging both authors and editors to think even more broadly. Two Key Contributor pieces highlight the contributions of researchers who have helped to push on these research
\end{abstract}

Lead Editors: L. D. Dierking and J. H. Falk.

L. D. Dierking and J. H. Falk, Editors for Special Issue, 2020 Vision: Envisioning a new generation of STEM learning research.

Lynn D. Dierking

dierkinl@science.oregonstate.edu

John H. Falk

falkj@science.oregonstate.edu

1 Free-Choice STEM Learning, College of Education, Oregon State University, 201K Furman Hall, Corvallis, OR 97331, USA

2 Free-Choice STEM Learning, College of Education, Oregon State University, 201L Furman Hall, Corvallis, OR 97331, USA 
boundaries, advancing science education research nationally and internationally. A final synthesis paper, a case study of research being conducted in a diverse, under-resourced community in Portland, Oregon provides one example of how the 2020 Vision research principles might be integrated into a comprehensive STEM learning research study.

Keywords STEM learning research $\cdot$ Research paradigms $\cdot$ Research principles · Lifelong learning · Twenty-first century

In an increasingly scientific and technological world the need for a science literate citizenry has never been greater, that is, individuals who can understand the fundamentals of STEM ideas and think critically about these issues, whether a STEM worker or an informed citizen voting on a science-related issue or engaging in some form of citizen science (National Academy of Sciences, National Academy of Engineering, and Institute of Medicine of the National Academies 2005). Yet, despite considerable investment of resources and efforts for many years, a range of indicators suggest that this ideal has yet to be accomplished (e.g., National Research Council 2007, 2011).

There are positive signs though. Long-standing indicators of overall public science literacy suggest incremental improvement (e.g., National Science Board 2014). In addition, an appreciation that STEM learning is not confined to the classroom, but is a part of the daily life of citizens has resulted in a blurring of the boundaries of where, when, how, why and with whom people learn the STEM that they know and use every day (National Research Council 2015). We now appreciate that STEM learning not only regularly occurs in schools and universities, but also in informal settings like museums, science centers, zoos and aquariums, when children and adults are at home, participate in community-based activities and after-school programs and across a wide range of digital media. This shift in understanding of the nature and process of STEM learning has initiated a growing awareness in the field that the questions and frameworks guiding STEM research need to reflect these new realities.

If STEM learning is truly a lifelong, life-wide and life-deep process, research designs must cut across diverse settings and investigate multiple contexts and media, rather than the historical approaches that have viewed learning within limited temporal, spatial and socio-cultural contexts (e.g., the third grade classroom, the introductory college physics course or fifth grade school field trip to a science center). New research paradigms and approaches, created by stepping back and looking more holistically at questions of the "what, when, where, why, how and with whom" of STEM learning, are needed. The new research principles that result from such reflections must better integrate learning realities that cut across time, setting, space, socio-cultural practices, STEM content and relationships between researchers, practitioners and learners themselves. Although a few innovative STEM research efforts have tried to accommodate these new realities (e.g., some of the work of the National Science Foundation funded learning centers such as Learning in Informal and Formal Environments Center, Center for Informal Learning and Schools and Center for Inquiry in Science Teaching and Learning, as well as the Free-Choice STEM Learning research program at Oregon State University), we believe the field could significantly benefit from a broadly inclusive, far-reaching dialogue on this topic.

This special 2020 Vision: Envisioning a new generation of STEM learning research issue of Cultural Studies of Science Education was supported in part by a grant from the 
U.S. National Science Foundation (US-NSF)'s Research and Evaluation on Education in Science and Engineering (REESE) program. These articles and Forum pieces represent one part of an on-going international conversation focused on the need for new STEM learning research paradigms. The 2020 Vision: Envisioning a new generation of STEM learning research project was characterized by an iterative process of input, debate, synthesis and dissemination.

\section{The 2020 Vision process}

In August 2009, with funding from the US-NSF REESE program, Oregon State University (OSU) hosted an international invitational conference-2020 Vision: Towards the Next Generation of STEM Learning Research-specifically designed to examine the opportunities, challenges and barriers to developing cross-cutting research questions and paradigms related to STEM learning research. In particular, the goal was to try to integrate more current understandings of learning into STEM learning research, as well as propose a range of new visions for possible future research directions. Each participant was asked to come to the meeting, prepared to discuss the following two questions:

- What do you consider to be the two most interesting/important issues that STEM learning research should be addressing in the next decade?

- What are the two most serious/problematic barriers (other than funding) that could prevent the STEM learning research community from making significant progress in the next decade?

Based on this "assignment," conference participants first recommended nineteen characteristics important to integrate within a cross-cutting research agenda that better reflected current understandings of science, technology, engineering and mathematics (STEM) learning among children and adults, in a variety of settings, including schools, but also contexts such as the home, community-based activities, after-school programs, the workplace, museums, science centers, zoos and aquariums, as well as across a wide range of digital media. After discussing, prioritizing and synthesizing the nineteen characteristics, working groups refined the list and each developed their ideas into an overarching "principle" that they felt STEM learning researchers should attempt to incorporate into their research designs in the next decade. The result was an initial draft of a set of recommended twenty-first century STEM learning research principles.

Although the four dozen participants who attended the initial 2020 Vision meeting were selected to be broadly representative of the field of STEM learning researchers (K-12, FCL/informal, post-secondary, media experts and so on), by design it was a small gathering and thus not fully encompassing the broader STEM learning research community. So following the meeting, 2020 Vision draft recommendations were vetted throughout 2009 and 2010 via posts on the 2020 Vision website, through presentations and discussions at several international science education conferences and meetings attended by the larger community of STEM learning researchers (e.g., the February 2010 American Association for the Advancement of Science (AAAS) annual meeting; the March 2010 NSF-Research and Evaluation on Education in Science and Engineering-REESE PI Summit; the March 2010 NARST annual meeting; the June 2010 NSF-Innovative Technologies for Teachers and Students Afterschool Convening: Advancing a Shared Research Agenda, a June 2010 NSF-funded Conference on Science Education Policy; at a workshop focused on 
Behavioral and Social Sciences in STEM Education hosted by the NIH Office for Behavioral and Social Sciences Research in July 2010; and the October 2010 Association of Science-Technology annual meeting).

At these meetings researchers were asked the same two questions that 2020 Vision participants had been asked, and then were presented with the draft principles that had emerged from the 2020 Vision meeting. They were encouraged to provide frank feedback and input, both on what had resulted from the meeting, but also on anything they felt was missing from the recommended research principles.

With feedback and input from these varied research groups, the 2020 Vision team revised the original key set of research principles. As before, the major goal of this aspect of the initiative was to help build bridges across diverse research communities in order to foster dialogue and synergies, making particular efforts to bridge the differences between those historically focused on: early childhood, K-12, post-secondary education and informal/free-choice settings. In addition, the initiative also strove to break down silos between science, technology, engineering and mathematics (STEM) content professionals, and build meaningful connections between research and practice within and across these diverse learning communities. From this process, six key cross-cutting principles emerged as fundamental to STEM learning research in the twenty-first century:

Principle 1 Frame STEM learning research within the broader social-cultural-political contexts of the needs and concerns of the larger global society.

Principle 2 Examine learning as a cultural process, involving varied repertoires of practice across learners' everyday lives, particularly non-dominant communities, seeing how these connect with practices in STEM disciplines.

Principle 3 Rethink the coordination and integration of STEM content and pedagogy in ways that more accurately reflect learning as a lifelong process that occurs across settings (e.g., early childhood, K-12, higher education, informal), situations (school, work and leisure time) and time frames.

Principle 4 Given the vastness of STEM what STEM content is actually worth learning, is it possible or even worthwhile for an individual to have a working understanding of all STEM topics.

Principle 5 Examine how and why to meaningfully engage practitioners from across the learning landscape in the research enterprise.

Principle 6 Describe how existing and emerging technologies and new media are and will continue to shape and redefine the content and practice of STEM learning research.

In the spring and fall of 2011 we invited scholars with expertise in each of the research areas to prepare draft papers and make a public presentation at OSU as part of the 2020 Vision symposium series. The goal was to further vet these initial ideas prior to compiling their original papers, along with Forum pieces, into a special issue of Cultural Studies of Science Education. After peer review, authors revised their papers in 2012 and Forum authors were invited to respond and extend the conversation. Collectively, these efforts were designed to create an ongoing, in-depth dialogue about the critical issues facing STEM learning researchers in the coming decades.

This issue includes a series of original papers and Forum pieces. Five papers are based on presentations at the 2020 Vision symposium series, each focused on a different research 
principle. Unfortunately, the author of the Principle 6 paper, James Gee, did not revise his draft, leaving the special issue without a paper devoted to this important research principle. Fortunately though, demonstrating just how critical existing and emerging technologies are in shaping and redefining STEM learning and STEM learning research, several authors in this issue do discuss the role of technologies, as they consider the other five principles. There also is a final synthesis paper, providing one example of how the 2020 Vision research principles might be integrated into comprehensive STEM learning research (and practice).

The associated Forum pieces critically examine a recommended research approach, in some cases, challenging both authors and editors to think even more broadly and holistically. There also is a rejoinder to one of the Forum pieces. Two Key Contributor pieces highlight the contributions of researchers who have helped to push on these research boundaries throughout their careers, advancing science education research nationally and internationally.

\section{Overview of contributions}

Principle 1 Frame STEM learning research within the broader socio-cultural-political contexts of the needs and concerns of the larger global society.

The first section of the issue focuses on the importance of framing STEM learning research within the broad social-cultural-political contexts of the larger global society and includes an original paper by Dana Zeidler and an associated Forum piece by Kenneth Tobin. In his paper, "STEM education: A deficit framework for the twenty-first century? A sociocultural response," Zeidler questions the current focus in science education research on narrowly defined STEM-related goals, arguing that such goals, by their very definition, are deficitoriented. He asks two fundamental and provocative questions: What does an educative experience embedded in STEM mean within the daily lives of citizens? And, what is omitted by such a vision? Zeidler suggests that it is important to ask the second question, not only in the context of formal and informal settings, but in the context of how these experiences play out over a person's lifetime, maintaining that framing science education research in a sociocultural perspective with socioscientific goals is an alternative, more asset-based approach.

In Tobin's Forum piece, "Collaborating on global priorities: Science education for everyone, any time and everywhere," he extends the conversation, focusing on the urgency to educate all humans about the science-related grand challenges they face, such as global warming and wellness. He argues that since significant changes are needed in human lifestyles, the current emphasis on preK-12 science education must be expanded to have relevance for all citizens, irrespective of age, location, language proficiency, economic resources, religion, gender, sexual preference, and level of prior education. He explores the use of a multilogical framework to select science content that has high relevance to sustainability, wellness, and well-being, and transform science education in ways that focus on education for a literate citizenry (birth through death) and responsible action, connected to the grand challenges of the present, at local, national, and global levels.

Principle 2 Examine learning as a cultural process, involving varied repertoires of practice across learners' everyday lives, particularly non-dominant communities, seeing how these connect with practices in STEM disciplines. 
The next section of the issue discusses the necessity for STEM education research, in this case mathematics, to examine learning as a cultural process, involving varied repertoires of practice across learners' everyday lives, with a particular focus on the importance of connecting the daily lives of non-dominant communities to STEM discipline practices. The section includes an original paper, "STEM learning research through a funds of knowledge lens," by Marta Civil, an associated Forum piece, "Stories of learning, identity, navigations and boundary crossings in STEM in non-dominant communities: New imaginaries for research and action," by Jrène Rahm and a rejoinder to Rahm by Civil.

In her original paper, Civil builds on her work in funds of knowledge and mathematics education, presenting three vignettes that raise provocative questions about the connections between in-school and out-of-school mathematics: How do we define competence? How do task and environment affect engagement? What is the role of affect, language, and cognition in different settings? These examples highlight the complexity of moving across different domains of STEM practice-everyday life, school, and STEM disciplines. Civil goes on to propose several areas for further research, including the nature of everyday STEM practices, language choice, and different forms of engagement.

In Rahm's Forum piece, she suggests that Civil's paper can be read as a story of Civil's trajectory as a researcher of everyday and school mathematics over time, grounded in sociocultural historical theory. She builds on Civil's work by exploring three issues: (1) the grounding of STEM research in studies of learning, narrowly defined, and what this may imply within the context of multilingualism and transculturism; (2) how funds of knowledge put into question what counts as science; and, (3) some of the methodological challenges Civil's paper raises. She concludes by commenting about the future of the STEM field and equitable science.

Civil's rejoinder focuses on four themes that emerged from her reading of Rahm: (1) the importance of the histories of youth of immigrant origin; (2) Rahm's comments on globalization, a topic that has been discussed earlier in other CSSE issues, as well as by Tobin and Zeidler in this issue; (3) the theoretical lens that Rahm brings to her research; and, (4) the methodological issues she discusses. Civil highlights Rahm's humanizing component and her call to understand the complexity of immigration, appreciating the asset-based question: What are we doing in our global settings to build on youths' diversity of experiences and backgrounds as a resource for STEM learning?

\section{Key contributors}

We continue the tradition in this issue of CSSE, of honoring Key Contributors to the field of science education, by observing either an institution supporting science education research, and/or a scholar whose work has influenced a growing body of research in science education. This particular key contributor piece is connected to the larger theme of this issue, and in particular, the papers in the previous section. A. Susan Jurow recognizes Kris Gutiérrez, Distinguished Professor in Literacy Studies and Learning Sciences and Human Development at University of Colorado, Boulder. In Kris Gutiérrez: designing with and for diversity in the learning sciences, Jurow reviews the significance of the theoretical and practical contributions that Gutiérrez has made to research in science education. Her pioneering ideas about design and equity have inspired scholars to investigate how to leverage learners' everyday practices to make meaningful connections to disciplinarybased knowledge and skills. Her work has provided invaluable direction about how to create and foster more equitable futures through critical understanding of cultural diversity as a resource for transformative learning. 
Principle 3 Rethink the coordination and integration of STEM content and pedagogy in ways that more accurately reflect learning as a lifelong process that occurs across settings (e.g., K-12, post-secondary, informal), contexts and situations (school, work and leisure time) and time frames.

The third section of the issue focuses on the need to rethink the coordination and integration of STEM content and pedagogy to more accurately reflect learning as a lifelong process that occurs across settings contexts and situations, and time frames. It includes an original paper by William Penuel and a Forum piece by Wolff-Michael Roth.

In Penuel's original paper, "Studying science and engineering learning in practice," he posits that the key goal of science and engineering education is to provide opportunities for people to access, interpret, and make use of science and engineering to address practical human needs, yet most education research, focuses on how best to prepare students in schools to participate in forms of science and engineering practices that resemble those of disciplinary experts. He argues that education research is needed that focuses on how people use science and engineering in social practices. Drawing upon social practice theory, he maintains that learning is an essential part of these activities, not only because people access and make use of science knowledge while participating in these practices, but also because participation transforms the ways that people imagine themselves and expands their possibilities for action. He believes that research can inform and support these efforts, both directly and indirectly, by accounting for the conditions of science and engineering learning and by diagnosing inequities in access to science and engineering that might address pressing human needs.

Roth's paper, "On the societal nature of praxis and organic research," presents an approach built on societal-historical activity theory that also takes activism as a major category for theorizing participation, thus allowing researchers to empirically consider the production of inequity and restrictions to access science and engineering that are characteristic of many societies.

\section{Key contributors}

The second key contributor piece by Léonie Rennie, "John Falk and Lynn Dierking: building the field of informal/free-choice science education" recognizes Falk, Sea Grant Professor of Free-Choice STEM Learning, Oregon State University and Director, Institute for Learning Innovation, and Dierking, Sea Grant Professor of Free-Choice STEM Learning and Associate Dean for Research, Oregon State University. Rennie discusses their on-going efforts, in both their collaborative and individual work, to highlight the critical importance of "context" in science learning, a concept that has underpinned their academic contributions to science education research overall, and specifically to the field of informal/free-choice science learning research. Rennie also notes that although their interests and skills overlap in complementary ways, both have made significant individual contributions; Falk in his work on identity and impact, and Dierking in her work on community, youth, family and equity. Their commitment to innovation as science education leaders and scholars is demonstrated by their vision for this special issue's theme, and the SYNERGIES project, within a diverse and under-resourced community in Portland, where they are attempting to re-conceptualize and collaboratively reconfigure inschool and out-of-school science learning as a complex, integrated ecosystem. This project is highlighted in the final synthesis paper. 
Principle 4 Given the vastness of STEM what STEM content is actually worth learning, is it possible or even worthwhile for an individual to have a working understanding of all STEM topics?

The fourth section of the issue focuses on STEM content and addresses what STEM content is actually worth learning, posing the question of whether it is possible or even worthwhile for an individual to have a working understanding of all STEM topics. It includes an original paper by Grace Reid and the late Stephen Norris and an associated Forum piece by Martin Storksdieck.

In their original paper, "Scientific media education in the classroom and beyond-a research agenda for the next decade," Reid and Norris posit that scientific media education (SME), which provides learners the ability to draw upon knowledge of media and science, in order to choose, understand, evaluate, and respond to representations of science across diverse media genres, is the most important content area that can be taught in and out of the science classroom. Thus rather than focusing on which individual STEM disciplines or topics to include or not, they identify a research agenda focused on scientific media education. They argue for making scientific media education a key content area in both formal and informal science learning environments with particular focus on those research avenues designed to better understand: (1) limitations in current practices of scientific media education; (2) what scientific media education should look like in the future; and (3) strategies that might alleviate the barriers to implementing new and improved scientific media education.

In Storksdieck's Forum piece, "Critical information literacy as a core skill for lifelong STEM learning in the twenty-first century: Reflections on the desirability and feasibility for widespread science media education," he maintains that there are issues with Reid and Norris' approach to the problem of selecting STEM content-both how they define the problem and how they propose solving it. Furthermore he argues for the need for a stronger intellectual/research foundation than they recommend. He concludes that making SME an integral part of STEM education is unrealistic, and instead offers the broader concept of information literacy, which better aligns with the current strong movement to conceptualize STEM education through science and engineering practices and within the broad goals of strengthening learners' twenty-first century learning skills. Although the focus of Storksdieck's paper is not on Principle 6, "Describe how existing and emerging technologies and new media are, and will continue to shape and redefine the content and practice of STEM learning research," his Forum piece does raise important considerations vis-à-vis the role that existing and emerging technologies and new media play in STEM learning.

Principle 5 Examine how and why to meaningfully engage practitioners from across the learning landscape in the research enterprise.

The fifth section of the issue focuses on the need to examine how and why to meaningfully engage practitioners from across the learning landscape in the research enterprise. It includes an original paper by Shawn Rowe.

In Rowe's paper, "Re-authoring research conversations: Beyond epistemological differences and toward transformative experience in professional development of educators," he discusses the commonplace concern among education researchers studying learning in both formal and informal learning contexts that many educators, both master teachers and those practicing the craft as novices, do not embrace educational research. Primarily viewed as a deficiency on the part of teachers and the profession of teaching, speaking 
from his own experience working with classroom teachers and educators in a wide range of out-of-school settings, Rowe suggests this has more to do with researchers and the nature of the research being conducted, than oft-noted reasons that research is too difficult to understand, unrelated to practice and that teachers' and researchers' epistemologies differ. He extends the conversation beyond epistemology, by raising additional issues related to: (1) the presentation of self in the teaching profession; (2) research as a tool that often conflicts, and, in many cases, transgresses its subjects' opportunities to author their own life experiences and self; and, (3) the role of re-authoring/re-narrativizing in moving beyond transgression to transformation, by bringing educator's voices to the table as partners in authoring a joint vision of teachers, teaching, and we would argue, research. In this vein, Rowe's paper connects to earlier papers urging new, more participatory approaches to research (Tobin, Penuel, Civil, Rahm), which not only demonstrate how people access and make use of science knowledge while participating in science (and engineering) practices, but also document how such participation can transform learners' views about what science is, who does it and their relationship to it, potentially encouraging further participation and action.

\section{Integrating the 2020 Vision research principles}

A final synthesis paper, "The SYNERGIES project: A 2020 Vision case study", authored by John Falk, Lynn Dierking, Nancy Staus, Jennifer Wyld, Deborah Bailey and William Penuel discusses an on-going longitudinal study being conducted in a diverse, underresourced community in Portland, Oregon, with the hope of measurably improving STEM learning, interest and participation, both in school and out of school for middle schoolaged youth and their families. Although the earlier papers and Forum pieces provide innumerable research ideas and directions, and each offers a big view, they focus on a specific aspect of the 2020 research vision; in great part, because that was the charge authors were given. We write this final paper to provide a synoptic view of what future STEM learning research could look like, providing one example of how the 2020 Vision research principles might be integrated into a comprehensive STEM learning research (and practice) effort.

Organized around the original six research principles, authors examine how each is integral to this research effort with a design attempting to: (1) more accurately reflect learning as a lifelong process occurring across settings, situations and time frames; (2) take into account the broader socio-cultural-political contexts of the needs and concerns of the larger global society; (3) examine learning as a cultural process, involving varied repertoires of practice across learners' everyday lives; (4) consider what STEM content is worth learning; (5) directly involve practitioners (and learners) in the research process; and, (6) document how existing and emerging technologies and new media are, and will continue, to shape and redefine the content and practice of STEM learning research. It is an ambitious effort and we discuss the challenges and successes thus far.

In closing, we would like to thank CSSE's Editorial Board for providing us the opportunity to publish these papers in this special issue to foster on-going dialogue and debate about the future of science education research broadly writ. We hope that the papers, and the consequent conversations, enable us as a community of researchers to be proactive as we move forward, embracing new ideas and approaches to conducting research in the twenty-first century. 


\section{References}

National Research Council. (2007). Rising above the gathering storm: Energizing and employing America for a brighter economic future. Washington, DC: National Academies Press.

National Research Council. (2011). Successful STEM education: A workshop summary. A. Beatty, Rapporteur. Committee on Highly Successful Schools or Programs for K-12 STEM Education, Board on Science Education and Board on Testing and Assessment. Division of Behavioral and Social Sciences and Education. Washington, DC: The National Academies Press.

National Research Council. (2015). Identifying and supporting productive STEM programs in out-of-school settings. Washington, DC: National Academy Press.

National Science Board. (2014). Science and engineering indicators: 2013. Washington, DC: U.S. Government Printing Office.

Lynn D. Dierking is Sea Grant Professor of Free-Choice STEM Learning and Associate Dean for Research, Oregon State University. Prior to joining OSU, Dierking was Associate Director and Senior Researcher at the Institute for Learning Innovation (a not-for-profit learning research and development organization devoted to free-choice learning) for 14 years. Dierking's research focuses on community, youth, family and equity in after-school-, home-, community- and museum-based contexts, particularly with groups historically under-represented in STEM.

John H. Falk is Sea Grant Professor of Free-Choice STEM Learning, Oregon State University, and Director, Institute for Learning Innovation (2.0). Prior to joining OSU, Falk founded and directed the Institute for Learning Innovation (1.0) in Annapolis, Maryland, a not-for-profit research and development organization devoted to understanding and facilitating free-choice learning. Falk's research focuses in two key areas: (1) how the self influences learner choice and control; and (2) the role of free-choice learning institutions on public understanding of STEM. 